\title{
श्रीगंगा का प्राचीन साहित्यिक एवं धार्मिक महत्त्व
}

देवेन्द्र कुमार गुप्ता एवं रविन्द्र कुमार

सारांश

प्रस्तुत अनुसन्धान का उद्देश्य गंगा की महिमा के विषय में ज्ञान प्राप्त करने और उसकी ऐतिहासिक एवं सांस्कृतिक पृष्ठभूमि को समझने का प्रयास है। भारतीय जनमानस के लिए गंगा भारत की प्राचीन संस्कृति और सभ्यता की प्रतीक रही है। अपने स्वरूप व प्रवाह में निरन्तर बदलाव लाने पर भी अपने मूल रुप में तो वही गंगा ने युगों-युगों तक एक समूची सभ्यता को न केवल सिंचित किया है बल्कि उसका भरण-पोषण भी किया है। गंगा शाश्वता का प्रतीक है तथा कला, पौराणिक कथाएँ एवं साहित्य सभी उसका गुणगाण करते हैं। गंगा परम्परा, पुराण, कला, संस्कृति एवं इतिहास से जुड़ी हुई है। उसका उल्लेख हमें प्राचीन भारतीय वाड.मय में स्थान-स्थान पर मनन करने के लिए मिलता है। वैदिक काल से लेकर पूर्व मध्यकाल तक गंगा विभिन्न स्वरुपों में समाई हुई है। वैदिक काल में गंगा का धार्मिक व गंगाजल के रुप में चिकित्सा की दृष्टि से महत्त्व रहा है। इसके पश्चात महाभारत, रामायण काल में गंगा को मोक्ष प्रदात्री के रुप में मान्यता मिली। मौर्य काल में गंगा को व्यापारिक दृष्टि से महत्त्वपूर्ण समझा गया। इसके पश्चात पौराणिक काल के अर्न्तगत गंगा का दैवीय स्वरुप देखने को मिलता है। समय के साथ धीरे-धीरे सभ्यता एवं संस्कृति में बदलाव आता गया लेकिन गंगा जी की महिमा का गुणगान, यशोगान सम्पूर्ण संसार में वैदिक काल से ही चला आ रहा है। इसलिए गंगा जी का वैभव असीम है।

कूट शब्द - भारतीय साहित्य, वेद, रामायण, महाभारत, उपनिषद, पुराण, धार्मिक महत्व एवं गंगा।

अनन्त काल से लेकर आज तक गंगा, हिरण्यगर्भा, अमृतवाहिनी, त्रिपथगा, पतितपावनी, मोक्षदायिनी आदि अनेक नामों से भारतीय वाड.मय में समाई हुई है। भारतीय सभ्यता को नया रूप देने में गंगा की कितनी महत्वपूर्ण भूमिका रही है, इस पर वेदों से लेकर आधुनिक युग तक अनेक रूपों में सामग्री उपलब्ध है यदि हम यह कहें कि गंगा की पौराणिकता व पवित्रता की तुलना संसार की किसी भी नदी से नहीं की जा सकती है, तो अतिश्योक्ति नहीं होगी। भारतीय नागरिकों की आत्मा को प्रमुदित करने वाली यह जल प्रवाहिनी प्रत्येक युग में भारतीय सभ्यता के इतिहास की प्रेरणा रही है। भारतीय सभ्यता के इतिहास में इसकी भूमिका अद्वितीय है। इसी के तट पर इतिहास पूर्व सभ्यता का विकास हुआ है।

गंगा मात्र एक नदी नहीं है, वह एक आसथा है, धर्म है, जीवनदायिनी है, मंगलकारिणी है, सुखदायिनी और दुखहारिणी है। उस मानवता की, जिसने उसके भौतिक अस्तित्व को देवनदी का स्वरूप व जल को चरणामृत के रूप में गृहण किया है। वेदों से लेकर आद्योपरांत भारतीय वांगमय का शायद ही ऐसा गौरव ग्रन्थ होगा जिसमें गंगा की महिमा का वर्णन न हो। गंगा का भारतीय जनमानस के साथ बड़ा गहरा सम्बन्ध है। प्राचीन काल से ही भारतीय मनीषियों का गंगा के प्रति पूज्य भाव रहा है। यूँ तो प्राय: सभी तीर्थों की महिमा अकथनीय है परन्तु भगवती गंगा के सम्बन्ध में तो प्राचीन भारतीय साहित्य में अनेकों स्थलों पर वर्णन विद्यमान है।

\section{प्राचीन भारतीय साहित्य में गंगा का यशोगान-}

\section{वेदों में गंगा}

सर्वप्रथम वैदिक वाड.मय में अनेक ऐसे मन्त्र हैं जिनमें गंगाजल की लोकोत्तर महिमा का विशद वर्णन प्राप्त होता है। यहाँ यह बताना आवश्यक न होगा कि अलग-अलग पन्थों में भी किसी न किसी स्थान को पवित्र मानकर यात्रा करने की प्रथा विद्यमान रही है। इसलिए गंगा का वेदोक्त महत्त्व सभी विद्वत जनों के मनन करने योग्य है। ऋग्वेद के दसवें मण्डल के नदी सूक्त में गंगा के विषय में सर्वप्रथम मन्त्र पढ़ने या मनन करने के लिए प्राप्त होता है (ऋग्वेद, $10 / 75 / 05)$ । गंगा सप्त सैंधव प्रदेश की पूर्वी सीमान्त नदी थी, जिसका पूर्व से पश्चिम की प्रमुख नदियों के साथ गंगा तटवासी जन (गांगम्य) के रूप में उल्लेख हुआ है (ऋग्वेद, 06/45/31)। गंगा के लिए इस समय प्रयुक्त अन्य अभिधान शब्द जाह्नवी (ऋग्वेद, $03 / 58 / 06$ ) का भी ऋग्वेद में उल्लेख हुआ है।

अथर्ववेद में भी गंगाजल को दिव्यौषध प्रदान करने वाली कहा गया है कि गंगा आदि नदियाँ हिमालय से समुद्र में मिलती हैं और उन नदियों के मध्य में जो गंगाजल है वह दिव्य जल हृदय के दाह को दूर करने वाला दिव्यौषध प्रदान करे। मंत्रों से ज्ञात होता है कि गंगा एक सामान्य जलराशि नहीं अपितु औषधियों का सार तत्व है। अथर्ववेद में तन्त्र, मन्त्र, यन्त्र, औषधि 
गुप्ता एवं कुमार

आदि के मन्त्र दिये हैं। शायद समस्त दोषों को समाप्त करने के लिए एक मात्र गंगाजल ही साधन रहा होगा। इसलिए अनेक स्थलों पर गंगाजल न कहकर भेषज कहा गया है (अथर्ववेद, $06 / 24 / 03)$ । यजुर्वेद जो कि कर्मकाण्ड का द्योतक है, उसमें भी एक स्थल पर गंगा एवं हिमालय का सुन्दर उल्लेख हुआ है (यजुर्वेद, 21/2)।

यजुर्वेदकार ने इडा और असित पिंगला आदि नामों से गंगा, यमुना, सरस्वती आदि नदियों का ही सम्बन्ध माना है। उसमें कहा गया है कि योगाभ्यास से र्नान करके जीव शुद्ध हो जाते हैं। दूसरे स्थान पर 'यस्येमे हिमवन्तो महित्वा, यस्य समुद्रं रस्या सहाहुः कहकर यजुर्वेद के ऋषि ने हिमालय, अनन्त जल के भण्डार हैं तथा उसकी ओर दौड़ कर बहने वाली नदियों के निस्सीम विस्तार और सौन्दर्य की चर्चा की है (यजुर्वेद, $25 / 12$ )। प्राचीन काल से ही गंगा के सम्बन्ध में वेदों में अनेक स्थलों पर उल्लेख आया हैं जिससे कि सम्पूर्ण नदियों में गंगा को सर्वोच्च स्थान प्राप्त हुआ है। वेद हमें गंगा के प्रति श्रद्धा, विश्वास, पूजन, नमन एवं मातृत्व की प्रेरणा देते हैं; क्योंकि गंगा ही मुक्ति देने वाली है। वेद अपौरूषेय ग्रन्थ हैं, उसमें कहे गए वचनों के प्रति श्रद्धा का होना हिन्दू जनमानस की स्वाभाविक प्रकृति है।

\section{उपनिषदों में गंगा}

वेदों के अनुसार ही उपनिषदों में भी गंगा का विशद उल्लेख हुआ है जैसा कि छान्दोग्योपनिषद् के खण्ड-छः का प्रथम मंत्र स्मरण करने योग्य है यहाँ पर हम हृदय की नदियों का उल्लेख करते हुए शुक्ल (श्वेत गंगा) नील (यमुना) पीत (सरस्वती) का वर्णन है। जो कि नदियों के नाम हैं इनमें निरन्तर योगाभ्यास के द्वारा मानसिक र्नान करने से परमेश्वर की प्राप्ति हो जाती है; क्योंकि उपासना नदियों द्वारा करनी है। अतः आत्म कल्याण चाहने वाले व्यक्ति का इन आन्तरिक गंगा, यमुना, सरस्वती में निरंतर ध्यान के द्वारा स्नान कर ईश्वर को प्राप्त करना चाहिए (छान्दोग्योपनिषद्, 6/1)।

नारायणोपनिषद में गंगा का अतुलनीय वर्णन किया गया है। उसे सम्पूर्ण नदियों में श्रेष्ठ एवं पूजनीय माना है- अतः व्यक्ति विशेष को चाहिए कि गंगा का निरन्तर सेवन किया करें ताकि इहलोक में सुख भोगकर अन्त में मुक्ति प्राप्त कर सकें (नारायणोपनिषद्, 13/189-90)। विष्णु धर्मसूत्र के अनुसार संचित अस्थियों को गंगा में बहा देना चाहिए; क्योंकि जितने दिन अस्थियाँ गंगा में रहेगी, उतने सहस्त्र वर्षों तक मृत व्यक्ति स्वर्ग में रहेगा (विष्णु धर्मसूत्र, 19/11-12)। वर्तमान समय में भी लोग अस्थियों को नदियों में प्रवाहित करना मृतक के लिए नितान्त पुण्यदायक मानते हैं।

ब्राह्मण धर्म अनुयायी समाज ने संस्कृत को अपनाया और महावीर और गौतम जैसे ब्राह्मण धर्म विरोधी समाज सुधारकों
ने लोक भाषा को अपनाकर प्राकृत परम्परा को आगे बढ़ाया, इसी भाषा में गंगा सम्बन्धी उल्लेख कुवलयमाला में देखने को प्राप्त होता है। जबकि उन्होंने सनातन धर्म विरोधी होते हुए भी श्री गंगा जी के महत्व पर प्रकाश डाला है; क्योंकि महान पवित्र गंगा संगम में स्नान करने से पापों की मुक्ति एवं पुण्यों की प्राप्ति होती है। जो व्यक्ति गंगा से चिन्हित फल की कामना करता है उसे फल प्राप्ति हो जाती है (कुवलयमाला, $24 / 55$ )।

जातकों में (तक्क जातक, 63) में "गंगाया किलिस्साम" शब्द का उल्लेख आया है जो उसे जलविहार के सन्दर्भ में प्राप्त होता है (सिंह, 2009, पृ0122)। नवीन कुमार के अनुसार मिलिन्दपन्हो में हिमालय से निकलने वाली लगभग 500 नदियों के उल्लेख हैं, परन्तु उनमें से सदैव जल प्रवाहित करने वाली केवल दस नदियों को ही श्रेणी मे रखा गया है, वे है- गंगा, यमुना, असरावती, सरयू महीसिन्धु ,सरस्वती, विभावती, विटमसा तथा कन्दभाग। संभवतः शेष नदियों का उल्लेख इसलिए नहीं किया गया है; क्योंकि वे यदा-कदा सूख भी जाया करती थी। उपर्युक्त दस नदियों में गंगा को प्रथम स्थान दिया गया; क्योंकि उस समय भी गंगा का महत्त्व दीर्घकालीन रहा होगा (कुमार, 2004, पृ० 65)।

दिव्यावदान में गंगा स्नान की महत्ता बताई गई है कि प्राचीन काल से ही राजा से लेकर भिक्षुक तक अपने पापों को शमन करने के लिए गंगा स्नान किया करते थे और अपने को धन्य समझते थे। अतः गंगा इहलोक में गंगा सुखोपभोग करती है। परन्तु परलोक में भी सुख पहुंचाती है (दिव्यावदानम्, $1 / 2 / 72)$ ।

महात्मा बुद्ध ने भिक्षुओं के प्रश्न का प्रत्युतर गंगा के उदाहरण से देते हुए जल के विषय में बताया है। ललितविस्तार के अनुसार धर्मचक्र प्रवर्त्तन के समय जब सिद्धार्थ उत्तर की ओर चले, चारिका करते हुए पहले 'गया' पहुँचे। वहाँ से रोहितवस्तु, रोहिवस्तु से उरुबिल्वाकल्प और वहाँ से अणाल, अणाल से सारथिपुर पहुँचकर, गंगा नदी को पार करके वाराणसी महानगरी में निवास किया था (वैद्य, 1958, पृ० 296)। सत्यकेतु विद्यालंकार का मानना है कि मौर्य काल में गंगा और अनेक नदियाँ अवश्य ही इतनी अधिक बड़ी थीं, कि उनमें ऐसी महानावें चलती थीं, जिन पर शासक, नियामक आदि बहुत से कर्मचारी कार्य करते थे (विद्यालंकार, 1980, पृ० 320)। इस समय गंगा का व्यापारिक दृष्टि से महत्त्व रहा होगा।

सिन्धु और गंगा की श्रृंखलाओं की नदियों की बहुलता को मेगस्थनीज ने वर्णित करते हुए उन पर टिप्पणी की है कि "गंगा जो अपने उदगम स्थल पर 30 स्टेडिया चौडी है, उत्तर से दक्षिण की ओर बहती है और गंगारिदइ (गंगेरिडाई) की पूर्वी सीमा बनाती हुई समुद्र में जाकर गिरती है, गंगा जैसी ही विशाल एक और नदी है जिसे कहते है सिन्धु। यह गंगा के समान ही 
उत्तर से निकलती है और सागर मे जा गिरती है, यह नदी रास्ते में भारत की सीमा अंकित करती है" इन दो नदियों व उनकी सहायक नदियों के अतिरिक्त छोटी-बड़ी और भी बहुत सी नदियाँ है। मेगस्थनीज के वर्णन से हमें गंगा की भौगौलिक स्थिति की जानकारी प्राप्त होती है, साथ ही मौर्य काल में भी गंगा का स्वरुप वर्तमान की भांति असीम रहा होगा (शासत्री, 1969, पृ० 95)।

\section{रामायण व महाभारत में गंगा}

महर्षि वाल्मीकि कृत रामायण के अनुसार गंगा हिमालय की पुत्री थी, देवता देव कार्य के लिए हिमालय से माँग कर गंगा को स्वर्ग ले गये थे। गंगाष्टकम् में महर्षि ने गंगा का सुन्दर यशोगान गाया है (रामायण, 1/100)। वाल्मीकि जी ने एक स्थान पर प्रार्थना करते हुए लिखा है कि जो श्री मुरारि के चरणों से उत्पन्न हुआ है, श्री शंकर के सिर पर विराजमान है तथा सम्पूर्ण पापों का हरण करने वाला है, वह मनोहर गंगाजल मुझे पवित्र करे।

महाभारतकार ने गंगा को श्राद्धकर्म के लिए सर्वोत्तम माना है, गंगा के स्नान, तर्पण, उपवास आदि करने से वाजपेय यज्ञ का फल मिलता है (महाभारत, वनपर्व 84-65)। इसी प्रकार महाभारत में गंगा की महिमा का वर्णन करते हुए इसे समसामयिक कलियुग की पतित पावनी कहा गया है। कलि के तमस युग में, स्वर्ग से आई नदी 'गंगा' ही पापियों का उद्धार करने में समर्थ होगी। इसके दर्शन मात्र से असीम आनन्द की प्राप्ति होती है (महाभारत, वनपर्व, $85,90,94,96$ )। गंगा जैसा कोई तीर्थ नहीं और केशव जैसा कोई देव नहीं (अनुशासन पर्व, $84 / 11-15)$ में लिखा है कि भीष्म पितामह ने गंगाद्वार में अपने पिता का श्राद्ध किया था, जिसमें पिण्ड लेने के लिए उनके पिता महाराज शान्तनु का हाथ प्रकट हुआ था। आश्रम वासिक पर्व (39/14-20) के अनुसार धृतराष्ट्र, गान्धारी, और कुन्ती ने गंगाद्वार में देहत्याग कर स्वर्ग प्राप्त किया था। युधिष्ठिर ने इनका श्राद्धकर्म गंगाद्वार में ही सम्पन्न कराया था। इसके साथ ही युधिष्ठर द्वारा गंगाद्वार में अस्थि प्रवाह का किया जाना भी उल्लिखित है। वर्तमान में भी इसी परम्परा का ही प्रचलन देखने को मिलता है।

\section{पुराणों में गंगा}

पुराणों के अन्तर्गत सर्वप्रथम ब्रह्मपुराण के 116वें अध्याय में गंगा विषयक कथाएँ प्राप्त होती हैं। इनमें ब्रह्मा एवं औषधियों का संवाद है। औषधियाँ बह्मा से पति प्राप्त होने का वर मांगती हैं। ब्रह्मा उन्हें पति प्राप्ति का उपाय बताते हैं कि तुम गंगाजी की स्तुति करो वही तुम्हे पति प्राप्ति का आशीर्वाद देंगी। पुनः औषधियाँ गंगा जी की स्तुति करती हैं (बह्मपुराण, 119/9-11)।
इसी प्रकार पद्मपुराण में महर्षि व्यासदेव ने गंगा की महत्ता बतलाते हुए विप्रों से कहा - विप्र गणों! जो साधारण जन्म वाले पुरुष हैं और अपनी सद्गति होने का चिन्तन किया करते हैं, उन पुरुष और स्त्रियों को चाहिए कि गंगा जी का दर्शन करें। भागीरथी गंगा केवल उसके दर्शन के लिए ही पाप का विनाश कर देती है। भगवती गंगा के र्मरण मात्र से ही समस्त पातकों का नाश हो जाता है (पदमपुराण, 2/12)। विष्णु पुराण के अनुसार गंगा जी का प्राक्ट्य भगवान विष्णु के पांव के अंगुष्ठ भाग में हुआ है (विष्णुपुराण, 4/30-31)। शिव पुराण के अनुसार गंगा प्राकट्य गंगा सप्तमी को माना जाता है (गौनियाल, 2002, पृ० 15)। श्रीमद्भागवत जी के नवम् स्कन्ध के नवम् अध्याय में गंगावतरण की कथा आती है (गौनियाल, 2002, पृ० 18)। भागवत पुराण की भाँति वायुपुराण में महर्षि व्यास ने गंगा में श्राद्धकर्म करने के लिए उत्तम तीर्थ माना है कि- पुण्य कर्म परायणों में समुद्रान्त में केवल एक श्राद्ध करने का विधान देखा है। गंगा, धर्मपृष्ठ ब्रह्मसरोवर गया गध्रकुट प्रभृति तीर्थों में श्राद्ध दान का महान फल है (वायुपुराण, $77 / 96$ )।

नारद पुराण में गंगा की महत्ता का उल्लेख किया गया है- गंगा के समान कोई तीर्थ नहीं है और "माँ" के समान कोई गुरु नहीं है। नारद पुराण के सदृश ही अग्निपुराण में अग्निदेव ने गंगा का सुन्दर वर्णन किया है। ब्रह्मवैवर्तपुराण में गंगोत्पत्ति कथन में कृष्ण भगवान कहते हैं कि गंगा की उत्पत्ति देवताओं के शरीर से हुई है। वराह पुराण में नदियों के अवतरण सम्बन्ध में सर्वोपरि गंगा का उल्लेख है। इसी प्रकार स्कन्द पुराण के काशी खण्ड एवं केदार खण्ड तो गंगा का माहात्मय एवं गुणगान से भरा पड़ा है। कूर्म पुराण के अनुसार गंगा तीर्थ समस्त कल्मषों को दूर करती हुई जीवात्मा को मुक्ति प्रदान करती है। मत्स्य पुराण में इतना कहा गया है कि गंगा की मृतिका का स्पर्श करने से ही व्यक्ति पाप मुक्त हो जाता है। गरुड़ पुराण के दसवें अध्याय में गंगा का विस्तृत वर्णन मिलता है। उसमें तो इतना लिखा है कि जब तक किसी प्राणी की अस्थियाँ गंगा जी में रहती हैं, उतने काल तक उसे स्वर्ग का सुख प्राप्त होता है (गौनियाल, 2002, पृ० 20-26, 29-31)। इस प्रकार समस्त वेद-वेदांगों, उपनिषदों एवं पुराणों में गंगा का उपाख्यान प्राप्त होता है। मनु स्मृतिः के एक श्लोक में गंगा का उल्लेख किया गया है (मनु स्मृति, 8/92)।

वासुदेव अग्रवाल के अनुसार पाणिनी ने अपने ग्रन्थ में सिंचाई करने वाली कई छोटी-बड़ी नदियों का उल्लेख किया है। जिसमें गंगा नदी भी सम्मिलित है जो कि वर्षा के बाद सिंचाई के प्राकृतिक साधनो में महत्त्वपूर्ण स्थान रखती थी (अग्रवाल, 2012, पृ० 207)। चीनी यात्री ह्वेनसांग ने एक विशाल झील का उल्लेख किया है और उसे सिन्धु, गंगा, आक्सस सीता आदि नदियों का उदगम स्थल बताया है। ये विशाल नदियाँ जम्बूदीप में स्थित थी। 
गुप्ता एवं कुमार

कालिदास के साहित्य में भी गंगा की महिमा का यशोगान किया गया है। कालिदास ने गंगा को मोक्षदायिनी, समस्त पाप विनाशिनी एवं बाधाओं को दूर करने वाली कहा है। कुमारसम्भव के प्रथम सर्ग में कालिदास ने गंगा के झरनों के आस-पास शिकार करने आये किरातों के विषय में कहा है (कुमारसम्भव, 1/15)। आज से लगभग दो हजार वर्ष पूर्व आचार्य चरक ने घोषणा की थी हिमवत्प्रभवा: पथ्या: हिमालय से उत्पन्न वनस्पतियाँ तथा गंगा असाध्य रोगों को दूर करने में सहायक हो सकती है (चरक संहिता, 1/20)। कालिदास ने विक्रमोवशीयम् के पांचवे अंक में गंगा-यमुना जी के संगम में स्नान करने को उचित महत्व प्रदान किया है। इस नाटक के पात्रों द्वारा गंगा-यमुना संगम में स्नान करने का उल्लेख हुआ है (विक्रमोर्वशीयम, $5 / 239$ )। रघुवंश में दूसरे सर्ग के छब्बीसवें श्लोक में गंगा जी के तट का उल्लेख हुआ है (रघुवंश, $2 / 26)$ ।

इसी प्रकार रघुवंश के षष्ठ सर्ग के चौरासीवें श्लोक में गंगा जी का वर्णन हुआ है। जिसमें उनके विषय में कहा गया है कि गंगा नदी का एक पर्याय है, यह हिमालय के गंगोत्री स्थान से निकलती है, इसी को गंगा या भागीरथी कहते हैं, सुहोत्र के पुत्र राजा जहनु ने गंगा नदी को अपनी पुत्री के रूप में गोद लिया। मेघदूत में गंगा की महिमा का गुणगान किया गया है (मेघदूत, $54,55,56,67,74)$ । विशाखदत्त ने मुद्राराक्षस में भी नदियों में गंगा को सबसे महत्त्वपूर्ण बताया है।

राजतरंगिणी में भी गंगा का उल्लेख हुआ है, जिसमें प्रथम लोहार वंश के राजा अनन्तदेव की मृत्यु होने पर उनकी अस्थियों को तन्वंग राज के सभी पुत्रों ने अस्थि विसर्जन हेतु, गंगा यात्रा आरम्भ की (राजतरंगिणी, 3/14)। यह श्राद्ध कर्म की दृष्टि से महत्वपूर्ण उल्लेख प्राप्त होता है। महाराज भर्तृहरि ने वैराग्य शतकम् में गंगा जी के विषय में वर्णन करते हुए लिखा है कि देखिये, गंगा स्वर्ग से शिवजी के मस्तक पर गिरी, फिर उनके सिर से हिमालय पर्वत पर, हिमालय पर्वत से पृथ्वी पर और पृथ्वी से समुद्र में गिरी। इससे मालूम होता है कि विवेक हीनों का पद पर सैकड़ों प्रकार से पतन होता है। कवि ने यहां गंगा का दृष्टान्त दिया है (वैराग्य शतकम्, 43)।

गंगा के यशोगान को गाने वाले पण्डितराज जगन्नाथ की 'गंगालहरी' तो विश्व विख्यात है। वे एक स्थल पर कहते हैं कि माँ गंगे इस संसार से जड़, ज्ञानरहित, अन्ध, पंगुल, जन्म के बहरे, गूँगे, ग्रहों से पीड़ित अर्थात् अतिक्लेश में फंसे जिसके पापों को दूर करने का कोई उपाय नहीं है, ऐसे पातकी मनुष्यों के पाप रूपी रोग हटाने को तुम अत्युत्त्म औषधि हो (गंगा लहरी', 15)। इसी प्रकार नरपति नाल्ह ने बीसलदेव रासो में गंगा स्नान का महत्व बताया है (बीसलदेव रासो, $2 / 205$ )। परमालरासो ने अनेक स्थलों पर गंगा का उल्लेख किया है (दास, 1976, पृ० 39)।
चन्दबरदायी कृत पृथ्वीराज रासो की प्राचीनतम प्रति में भी गंगा की महिमा का यशोगान किया गया है (द्विवेदी, 1985, पृ0 114)।

\section{धार्मिक महत्व}

भारत की अनेक धार्मिक अवधारणाओं में गंगा नदी को देवी के रूप में निरूपित किया गया। बहुत से पवित्र तीर्थस्थल गंगा नदी के किनारे पर बसे हैं जिनमें वाराणसी और हरिद्वार सबसे प्रमुख है। गंगा नदी को भारत की पवित्र नदियों में सबसे पवित्र माना जाता है। यह मान्यता है कि गंगा में स्नान करने से मनुष्य के सारे पापों का नाश हो जाता है। मरने के बाद लोग गंगा में राख विसर्जित करना मोक्ष प्राप्ति के लिये आवश्यक समझते हैं, यहाँ तक कि कुछ लोग गंगा के किनारे ही प्राण विसर्जन या अंतिम संस्कार की इच्छा भी रखते हैं। इसके घाटों पर लोग पूजा अर्चना करते हैं, ध्यान लगाते हैं। अपनी कामनाओं के दीपद्रोण लेकर असंख्य श्रद्धांलु तीर्थयात्री और गंगा तट पर आते हैं और 'गंगा मैया की जय' के साथ वे दीपद्रोण गंगा को साक्षात देवी मानकर उसके हिमषीतल जल में प्रवाहित कर देते है। इन लाखों-करोड़ों आस्थावान लोगों के लिए गंगा न केवल मरणोत्तर मोक्ष प्रदान करने वाली माँ है बल्कि इस आदि भौतिक जगत में भी वह माँ की तरह उन पर सुखों की वर्षा करती है। गंगा की तेज व शीतल धारा के प्रति स्नानार्थियों की जो धार्मिक और आध्यात्मिक भावानाएं हैं उनके कारण गंगा स्नान उनके लिए स्वर्ग प्राप्ति का सोपान है। स्नानार्थियों की इसी भावना ने गंगा को अप्रतिम महत्ता प्रदान कर दी है। गंगा में स्नान करने वालों की संख्या आमतौर पर अमावस्या, पूर्णिमा, एकादशी, संक्रांति, गंगा दशहरा, बैसाखी, अर्द्धकुम्भ और कुम्भ पर्वों पर कई - कई गुणा बढ़ जाती है। इस प्रकार से गंगा का धार्मिक महत्व बढ़ता जा रहा है।

\section{निष्कर्ष}

इस प्रकार वैदिक काल से लेकर पूर्व मध्यकाल तक गंगा विभिन्न स्वरुपों में समाई हुई है। वैदिक काल में गंगा का धार्मिक व गंगाजल के रुप में चिकित्सा की दृष्टि से महत्व रहा है। इसके पश्चात महाभारत, रामायण काल में गंगा को मोक्ष प्रदात्री के रुप में मान्यता मिली। वर्तमान में भी इसी परम्परा का अनुशरण किया जा रहा है। मौर्य काल में गंगा को व्यापारिक दृष्टि से महत्वपूर्ण समझा गया। इसके पश्चात पौराणिक काल के अर्न्तगत हमें गंगा का दैवीय स्वरुप देखने को मिलता है। धीरे-धीरे सभ्यता एवं संस्कृति में बदलाव आता गया लेकिन गंगा जी की महिमा का गुणगान, यशोगान सम्पूर्ण संसार में वैदिक काल से ही चला आ रहा है। इसलिए गंगा जी का वैभव असीम है।

गंगा जी भारत वर्ष की संस्कृति रूपी सुधा रस की संरक्षक है। यह विश्व का भाग्य ही था कि भगीरथ के तप की 
ऐसी पवित्र फल प्राप्ति हुई। जिनकी कपा से यह भूमि मंगलकारिणी बन गयी। वे संसार के दुख और पापों को नष्ट करने वाली और विपत्ति विनाशिनी गंगा जी धन्य है। अनेकशः संस्कृत काव्यकारों एवं साहित्यकारों ने अपनी-अपनी कृतियों में भागीरथी का यथाज्ञान के द्वारा वर्णन किया है। हिन्दी साहित्यकार भी प्रकृति की मनोज्ञता पर मुग्ध हुए हैं। यद्यपि सांसारिक दृष्टि से गंगा का सम्बन्ध प्रकृति के साथ एक सरिता के रूप में होना चाहिए तथापि भारत में धार्मिक दृष्टि से गंगा का महत्व अत्यधिक है।

देवेन्द्र कुमार गुप्ता, पी-एच0डी०., प्रोफेसर; रविन्द्र कुमार, शोधार्थी, प्राचीन भारतीय इतिहास, संस्कृति एवं पुरातत्व विभाग, गुरूकुल कांगड़ी विश्वविद्यालय, हरिद्वार, भारत।

\section{सन्दर्भ सूची}

अथर्ववेद, $06 / 24 / 03$

ऋग्वेद, $03 / 58 / 06 ; 10 / 75 / 05 ; 06 / 45 / 31$

कुवलयमाला, 24 / 55

कुमारसम्भव, $1 / 15$

गंगा लहरी, 15

चरक संहिता, $1 / 20$

छान्दोग्योपनिषद्, $6 / 01$

दिव्यावदानम, $1 / 2 / 72$

नारायणोपनिषद्, $13 / 189-90$

पदमपुराण, $2 / 12$

बीसलदेव रासो, $2 / 205$

बह्मपुराण, 119/9-11

महाभारत, वनपर्व, 84-65, 90, 94, 96

मनु स्मृति, $8 / 92$
मेघदूत, 54-56, 67, 74

यजुर्वेद, $21 / 2 ; 25 / 12$

रामायण, $1 / 100$

रघुवंश, $2 / 26$

राजतरंगिणी, $3 / 14$

विष्णु धर्मसूत्र, 19/11-12

विष्णुपुराण, 4/30-31

वायुपुराण, 77 / 96

विक्रमोर्वशीयम, $5 / 239$

वैराग्य शतकम्, 43

अग्रवाल, वासुदेवशरण (2012). पाणिनिकालीन भारत वर्ष/ वाराणसी- चौखम्बा संस्कृत सीरीज।

कुमार्, नवीन (2004). प्राचीन भारत में सिचाई व्यवस्था (शोध ग्रन्थ)। गुरुकुल कांगड़ी विश्वविद्यालय- हरिद्वार।

गौनियाल, राजेन्द्र कुमार (2002). हिन्दी काव्य में गंगा (शोध ग्रन्थ)। गुरुकुल कांगड़ी विश्वविद्याालय- हरिद्वार।

दास, श्यामसुन्दर (1976). परमालरासो। बनारस- काशी नागरी प्रचारिणी सभा।

द्विवेदी, हजारी प्रसाद (1985). पृथ्वीराज रासो। इलाहाबाद- साहित्य भवन प्रा० लि०।

वैद्य, पी० एल0 (1958). ललितविस्तार (बौद्ध-संस्कृत ग्रन्थावाली-1)। बिहार, दरभंगा- मिथिला विद्यापीठ दरभंगा।

विद्यालंकार, सत्यकेतु (1980). मौर्य साम्राज्य का इतिहास/ मसूरी- श्री सरस्वती सदन।

सिंह, अनिल कुमार (2009). जातकों में वर्णित समाज/ वाराणसी- कला प्रकाशन।

शास्त्री, नीलकण्ठ (1969). नन्द-मौर्य युगीन/ दिल्ली- मोतीलाल बनारसी दास। 